\title{
A MODIFIED TECHNIQUE OF INTRAVENOUS ANAESTHESIA WITH MEPERIDINE AND SUCCINYLCHOLINE**
}

\author{
Col. N. H. McNally, C.D., MI.D., S/L H. H. Neily, C.D., M.'D., AND \\ S/L J. Bevort, M.D.
}

SINCE THE END of World War II, the use of intravenous anaesthesia for long or complicated procedures has diminished tremendously. In most hospitals, this technique is generally limited to short manipulative procedures and as the most pleasant method of inducing oblivion prior to the introduction of inhalation anaesthesia.

Occasions still arise, however, in which all of the common potent inhalation agents are contraindicated. In these circumstances, it is often advisable to revert to the use of drugs administered intravenously to maintain adequate degrees of anaesthesia and relaxation. Satisfactory ventilation can be attained by a variety of methods, all of which are safe and reliable.

The use of thiopentone for long periods tends to result in relatively slow recovery. Furthermore, when injections are given with (or too close to) depolarizing relaxants, precipitation results, a complication which is prone to interfere with the proper functioning of the intravenous infusion.

Although little has been published of the technique ${ }_{2}$ it is known that many anaesthetists have used intermittent injections of meperidine (Demerol) and succinylcholine, each for its own purpose, as a means of maintaining anaesthesia. Nitrous oxide/oxygen is commonly used to supplement these agents, employing a semi-closed system. Respiratory assistance is usually given by manual compression of the anaesthetic bag.

\section{APPROACH}

A combination of an unacceptable explosion hazard and use of adrenaline in a mixture employed for infiltration in various otolaryngology procedures (submucous resections, rhinoplasties, etc.) led us to avoid the use of ether, cyclopropane, and halothane in anaesthesia for these cases. It was our custom to employ a thiopentone-succinylcholine-intubation sequence for induction, followed by the meperidine or thiopentone and succinylcholine technique, as described. Dealing, as we were initially, with a patient population limited to persons of military age, we had the usual incidence of fasciculations following the initial injection of succinylcholine. Regrettably, we also noted a significant number of patients complaining of various degrees of post-succinylcholine muscle pain. Although we were not maintaining detailed records of this complication, we estimated that troublesome symptoms were occurring; in approximately 10 per cent of our cases. This figure is important when we, consider the tremendous decrease encountered unexpectedly after we modified our technique.

*From the Department of Anaesthesia, Natıonal Defence Medical Centre, Ottawa, Canada. 
In order to simplify our technique and permit better monitoring of ventilation, pulse and blood pressure, we decided to employ a prepared mixture of meperidine and succinylcholine in a continuous infusion. A study of statistics from a number of cases revealed that the total dosages of succinylcholine used were roughly double those of meperidine. We therefore prepared our infusion using $1.0 \mathrm{mg}$./cc. of succinylcholine and $0.5 \mathrm{mg} . / \mathrm{cc}$. of meperidine in 5 per cent dextrose-water solution.

Simple modification of a common technique does not normally warrant publication. However, the results attained by intensive application of this method of intravenous anaesthesia, together with the unexpected benefits accruing to the patient, make it worthy of comment in detail, in our opinion.

\section{Tecinsique}

\section{Premedication}

The immediate premedication used, in dosages varying with body weight, consists of meperidine and atropine, intramuscularly, 45 minutes to 1 hour prior to induction.

It is our practice to start an intravenous infusion of 5 per cent dextrose-water immediately before induction using an 18 or 19 gauge needle.

The anaesthetic mixture, consisting of $1.0 \mathrm{mg}$. succinylcholine per cc. and $0.5 \mathrm{mg}$. meperidine per cc. (contained in $500 \mathrm{cc}$. or $1,000 \mathrm{cc}$. of 5 per cent dextrose-water solution) is superimposed on the first infusion by means of another transfer set.

\section{Induction}

The superimposed set is clamped off until after administration of a "sleep dose" of thiopentone directly into the parent intravenous infusion near the needle. Abolition of the lid reflex is the indication for clamping the intravenous and opening the set delivering the meperidine-succinylcholine mixture. The anaesthetic mixture is allowed to run rapidly (100-150 drops/minute) until a pharyngeal airway can be introduced easily. During this interval we normally ventilate the patient by manual compression of the anaesthetic bag containing 100 per cent oxygen.

The technique varies depending on the procedure to be undertaken, and the adequacy of the airway, as indicated below.

1. Laryngoscopy or bronchoscopy. Where we use the Emerson "wrap-around" respirator routinely, the effectiveness of the seal can be tested within 1--2 minutes of induction. Respiratory rate, inspiration and expiration times, are adjusted until adequate tidal exchange has been obtained. This is usually accomplished by observing the movement of the anaesthetic bag. More accurate measurements may be performed by means of a Wright respirometer, if desired. As soon as adequate ventilation is obtained, the head is released to the operator and the drip is slowed to a maintenance level just sufficient to prevent diaphragmatic activity. The drip is discontinued as the bronchoscopist commences to withdraw the scope and an endotracheal tube is inserted and held in place until full reflex 
activity has returned. However, in a very high percentage of cases, insertion of the tube is impossible owing to the rapidity with which the reflexes return.

2. Ear, nose, and throat and dental surgery. In these cases endotracheal intubation is performed routinely, either via the nose or mouth, depending on the type of surgery proposed. Intubation is performed as soon after commencement of the drip as possible. This can normally be accomplished after delivery of 80-100 cc. of the mixture. "In this type of surgery, the intravenous anaesthesia can be supplemented by nitrous oxide, where such is available, the usual technique being to use it in a semi-closed system in proportions of 2:1 or 3:1 with oxygen. Ventilation can be controlled either manually or automatically,

It is interesting that this intravenous technique can be employed without the use of standard anaesthetic machines or gases. This was done in a number of instances to test its effectiveness for Field or Emergency use. Ventilation was then maintained by means of either an Oxford Inflating Bellows or an Ambu respirator. Both worked quite satisfactorily. In some cases, however, it was found advisable to add increments of meperidine or succinylcholine directly to the infusion when one or the other appeared to be inadequate in the mixture. It was felt that this would reduce the total dosage of the other agent. When intubation is performed, Lidocaine (Xylocaine) 4 per cent is customarily sprayed on to the cords, prior to insertion of the tube. Following intubation, surgery can be commenced fairly promptly.

3. General surgery. Where an adequate airway and satisfactory ventilation can be obtained without it, endotracheal intubation may be dispensed with. For most cases, however, we prefer intubation if for no other-reason than to eliminate gastric dilatation from continuous artificial ventilation. As noted in Table I, this technique was used in a wide variety of surgical procedures to test its feasibility. We have adopted it for all ear, nose, and throat surgery except tonsillectomy as the anaesthetic of choice.

\section{Maintenance-General}

During the course of the operation, the infusion is maintained at a rate just adequate to eliminate diaphragmatic breathing. Generally speaking, it has been found that $100 \mathrm{cc}$. ( $100 \mathrm{mg}$. succinylcholine and $50 \mathrm{mg}$. meperidine) are required for intubation and the commencement of surgical interference.

Towards the end of the procedure, the rate of administration is slowed considerably, and the infusion is discontinued during the application of dressings. Spontaneous respiration returns very quickly after cessation of the infusion. Extubation is effected when all reflexes have returned.

\section{Clinical Experience}

This report is based on experience with 160 cases in which the meperidinesuccinylcholine mixture was the principal anaesthetic. The ages of the patients ranged from 18 to 65 years. Several were relatively poor risk candidates because

\footnotetext{
"We have found this technique particularly useful for the/teaching of intubation, for it avoids the need to add increments of either agent. If the student has any difficulty, one need only discontinue attempts long enough to permit a short period of hyperventilation.
} 
of impaired cardiac or pulmonary functions. Anaesthetic times varied from 15 to 265 minutes. Five of our patients were females.

Table I shows the types of cases in which the technique was used, the average anaesthetic time for each procedure, and the average quantities of drugs administered.

TABLE I

\begin{tabular}{|c|c|c|c|c|}
\hline \multirow[b]{2}{*}{ Type of surgery } & \multirow[b]{2}{*}{ Number } & \multirow{2}{*}{$\begin{array}{l}\text { Average } \\
\text { duration of } \\
\text { anaesthesia, } \\
\text { minutes }\end{array}$} & \multicolumn{2}{|c|}{ Average quantities of drugs } \\
\hline & & & $\begin{array}{c}\text { Demerol, } \\
\text { mg. }\end{array}$ & $\begin{array}{c}\text { Succinylcholine, } \\
\text { mg. }\end{array}$ \\
\hline Submucous resection & 70 & 70 & 150 & 300 \\
\hline Tonsillectomy & 15 & 40 & 125 & 250 \\
\hline Rhinoplasty & 10 & 110 & 325 & 650 \\
\hline Caldwell-Luc & 2 & 105 & .500 & 1000 \\
\hline Antrostomy & 5 & 60 & 250 & 500 \\
\hline Bronchoscopy & 15 & 30 & 150 & 300 \\
\hline Bronchogram (intubation) & 8 & 15 & 50 & 100 \\
\hline Reduction fractured nose & 6 & 25 & $7 \tilde{5}$ & 150 \\
\hline Radical mastoidectomy & 2 & 210 & 300 & 620 \\
\hline Myringoplasty & 2 & 100 & 150 & 300 \\
\hline Dental extractions & 11 & 35 & 100 & 200 \\
\hline Gastrectomy & 3 & 180 & 275 & 800 \\
\hline Cholecystectomy & 2 & 100 & 250 & 500 \\
\hline Prostatectomy & $\overrightarrow{1}$ & 105 & \pm 25 & 910 \\
\hline Nephrectomy & 2 & 80 & 200 & +10 \\
\hline Appendectomy & 1 & $5 \overline{5}$ & 100 & 200 \\
\hline Splenectomy & 1 & 265 & 400 & 1000 \\
\hline Varicose vein stripping & 2 & 130 & 125 & 310 \\
\hline Lumbar synipathectomy & $\overline{1}$ & 85 & 350 & 730 \\
\hline Excision supraclavicular tumour & 1 & 165 & 620 & 2000 \\
\hline
\end{tabular}

\section{Results}

This technique proved satisfactory in all cases. Inductions were smooth and uneventful. Pulse rates and blood pressures remained quite stable, fluctuating only when anaesthesia was allowed to lighten unduly or ventilation was inadequate. There was no clinical evidence of cardiac irregularity except in cases already known to be abnormal in this respect. Cardiac and pulmonary problems were not aggravated in any way. Known asthmatics tolerated the use of this technique particularly well.

There was no case of prolonged apnoea due to succinylcholine. Every patient was retained in the recovery room until there could be no doubt in this regard. Small ( 1 ampoule) doses of "Emivan" were used to confirm full return of diaphragmatic and intercostal activity wherever there was any question of relaxant "hangover."

\section{Postanaesthesia}

Recovery from anaesthesia is surprisingly rapid. In many cases, patients awaken on the operating table, oriented and alert, within two to three minutes of cessation of the anaesthetic. We have seen many trying to remove the endotracheal tube or co-operating in its removal. They often chat quite intelligently with the anaesthetist and operating room staff very shortly after the procedure.

There is a tendency for patients to doze quietly during the first two to three 
hours after operation. They are aroused easily by spoken voice or light stimulus, however, and all their reflexes remain quite active. These features are considered of particular benefit where restlessness is undesirable (e.g., following ear, nose, or throat surgery). They are up and about shortly thereafter, however, when the surgery does not preclude such activity.

We monitor postoperative sedation carefully, and use levallorphan routinely, in conjunction with narcotics whenever these are deemed necessary. Our impression is that the requirement for sedation is reduced considerably in these cases.

It is significant, perhaps, that nausea and vomiting were so rare as to be negligible in our series. Each patient was visited daily for three days by a member of the department. Being concerned lest there be any recollection of the surgery, we ensured that each patient was questioned carefully on this point. Originally this was done verbally, later through the medium of a questionnaire, which is now completed by all patients $48-96$ hours after anaesthesia. In our series of 160 cases, there was no instance of any recall. A few did have vague memories of awakening with the endotracheal tube in place. This experience did not seem to have produced any emotion except surprise.

\section{Special Observations}

Perhaps the most striking result attained with this technique of anaesthesia was the low incidence of significant post-succinylcholine muscle pain. Of the 160 patients, only two developed the full-blown syndrome of muscle pains in the neck, thorax, shoulders, etc.

Of equal interest was the discovery that quite a few, when questioned closely and directly, did admit to some discomfort in the lower anterior chest. When asked to point to the area, they usually indicated an area over the xiphoid process and vicinity.

It should be pointed out that when we first started using this technique for ear, nose, and throat surgery, the effort was aimed, primarily, at simplifying the maintenance phase of anaesthesia. At this stage we were using a standard thiopentone-succinylcholine-intubation sequence, and accepting the fasciculations (sometimes of convulsive severity) as a necessary evil. The sudden absence of post-relaxant pain was first brought to our attention by the surgeon, who realized that he had had no complaint of such discomfort. We determined, then, that there had been 25 consecutive cases without pain, and henceforth kept a close check on this particular facet of the situation.

We interpreted this series as an indication that the fasciculations were of doubtful significance in the aetiology of post-succinylcholine pain, and certainly not the major factor. During the conduct of this study, many other surgical patients have received depolarizing agents by intermittent injections. The incidence of pain in these cases, although not alarming, has been much more frequent than in the meperidine-succinylcholine series. We have maintained files of the questionnaires received from all patients, and intend to study them more fully with a detailed comparison of incidence in mind. 
The two patients in our series who developed troublesome symptoms were reviewed as carefully as possible. The only comments noted on the records which might give a clue to aetiology concerned the level of anaesthesia maintained. It had been rather lighter than usual throughout the procedure for both of these -patients. Although this meant little to us at the time, it may give a possible clue to the reason for this complication.

It is our impression that the maintenance of complete muscle relaxation throughout surgery is important when succinylcholine is used. We attribute the incidence of mild discomfort in the anterior chest to the fact that, in these cases, some degree of intercostal muscle activity was permitted during the operation. If this is not permitted, and general muscle relaxation is ensured by adequate levels of anaesthesia, it is our impression that post-relaxant pain can be virtually eliminated. To this extent it is possible that the fasciculations may aggravate the situation only if anaesthesia and relaxation are not controlled adequately after induction.

We have been impressed by the striking similarities between post-relaxant muscle pain, and the stiffness and soreness experienced by untrained persons the day after unaccustomed, strenuous exercise. The two are actually indistinguishable, clinically. Presumably this similarity has been the reason for the assumption by many anaesthetists of a direct cause-and-effect relationship between the postinjection fasciculations and the pain which develops subsequently. ${ }^{1-6}$ It is difficult to convince oneself, however, that such relatively minor muscle contractions can be the prime factors leading to such distressing discomfort 24 hours later.

Investigation of the aetiology of postexercise muscle stiffness has been limited. It is generally conceded, however, that muscle anoxia and an unnatural accumulation of lactic acid with resultant impingement or stimulation of nerve plates during later activity form the basis for a physiological explanation. ${ }^{i}$

If post-relaxant pain is explainable on the same general basis as postexercise pain, then logical steps may be taken to prevent its development. Elimination of the fasciculations would certainly make sense, as a first step. Whether or not the depolarizing agent contributes to the aetiology by directly or indirectly limiting the elimination of lactic acid might bear investigation.

Meanwhile, it is our impression that prophylaxis can be effective if a few requirements are kept in mind:

1. Adequate ventilation must be assured throughout the effective action period of the relaxant. Employment of controlled respiration with moderate hyperventilation should ensure adequate oxygenation of the muscles.

2. Blood pressures and circulation must be kept as near normal levels as possible.

3. All muscle activity must be eliminated to the greatest extent possible durring the use of depolarizing agents. It is felt that failure to ensure the absence of intercostal and diaphragmatic muscle activity may account for the localization of mild degrees of discomfort in these areas.

4. Poor positioning on the operating table must be avoided since it may predispose to development of pain in some of the other muscle groups-notably those of the neck, shoulders, and arms. It may be presumed that malpositioning 
may contribute to a predilection for these muscles to be sites for pain, by restricting their circulation or forcing them into positions of relative tension.

5 . We have wondered, of late, about the possible protective role played by the dextrose in the intravenous infusion. This might well be worthy of study. At any rate, we recommend that the meperidine-succinylcholine be prepared in 5 per cent dextrose in water.

\section{SUMMARY}

A simple, safe, controllable technique of intravenous anaesthesia employing a mixture of meperidine (Demerol ${ }^{\circledR}$ ) and succinylcholine has been described. Our experience with the technique in 160 surgical procedures is discussed.

Although particularly useful for anaesthesia where the potent inhalation agents were contraindicated, this method was successfully employed for a variety of cases, with and without the aid of standard anaesthetic machines. Its possible use in Field and Emergency situations is mentioned.

The virtual absence of significant post-relaxant muscle pain, following use of this technique, aroused our interest. An hypothesis as to possible aetiological factors in the development of this common sequel to the use of depolarizing relaxants is advanced. Methods of prevention which appear to be effective are suggested.

\section{RÉsuMÉ}

Chez 160 personnes soumises à une intervention chirurgicale, les auteurs ont procédé à l'anesthésie par perfusion continue contenant $1.0 \mathrm{mg}$. $/ \mathrm{cc}$. de succinylcholine et de $0.5 \mathrm{mg}$./cc. de mépéridine dans un soluté aqueux de dextrose à 5 pour cent. L'induction se fait avec une dose de thiopentone suffisante pour provoquer l'inconscience; par la suite, la solution de mépéridine-succinylcholine est administrée rapidement de façon à permettre l'introduction facile d'un tube pharyngé. La ventilation est contrôlée soit à la main, soit par ventilateur, et l'anesthésie intra-veineuse peut être complétée par l'administration d'oxygène et de protoxyde d'azote.

A la suite de l'emploi de succinylcholine en perfusion, les auteurs furent frappés de la quasi-absence de douleur musculaire, comparativement à la fréquence de ces douleurs chez les malades avant l'introduction de cette solution combinée.

Quoique cette technique d'anesthésie soit utile surtout lorsque les agents inhalants puissants sont contre-indiqués, elle peut être utilisée pour tous les cas de chirurgie, et même conseillée dans les situations d'urgence.

\section{REFERENCES}

1. Burti.es. Muscle pains after Suxamethonium and Suxethonium. Brit. J. Anaesth. 33: 147 (1961).

2. Burtles, \& Tindall, M. E. Suxamethonium Chloride and Muscle Pains. Brit. J. Anaesth. 33: $24(1961)$.

3. Churchinl-Davidson, H. C. Suxamethonium (Succinylcholine) Chloride and Muscle Pains. Brit. Med. J. 1: 74 (1954). 
4. Foster, C. A. Muscle Pains That Follow Administration of Suxamethonium. Brit. Med. J. 2: $24(1960)$.

5. Morris, D. D. B., \& Duns, C. H. Suxamethonium Chloride Administration and Postoperative Muscle Pain. Brit. Med. J. 1: 383 (1957).

6. PrInce-White, F. Suxamethonium and Postoperative Muscle Pain. Brit. Med. J.'1: 761 (1957).

7. Best, Chas. H., \& Taylor, Norman B. The Physiological Basis of Medical Practice, 7th ed., sect. vir, chap. 62. Baltimore: The Williams \& Wilkins Co. (1961). 